\title{
Clinical relevance of donor-specific human leukocyte antigen antibodies after pediatric liver transplantation
}

\author{
WEI LIU ${ }^{1}, \mathrm{KAI}_{\text {WANG }}^{2}$, YAN-LI XIAO ${ }^{1}, \mathrm{CHUN} \mathrm{LIU}^{1}$, WEI GAO $^{2}$ and DAI-HONG LI ${ }^{1}$ \\ Departments of ${ }^{1}$ Blood Transfusion and ${ }^{2}$ Transplantation Surgery, \\ Tianjin First Central Hospital, Tianjin 300192, P.R. China
}

Received September 3, 2019; Accepted September 30, 2020

DOI: $10.3892 / \mathrm{etm} .2021 .10299$

\begin{abstract}
Donor-specific human leukocyte antigen (HLA) antibodies (DSAs) have a significant role in graft survival after pediatric liver transplantation. To understand the significance of DSAs, a retrospective cohort study of 48 pediatric liver transplant recipients with posttransplant serum samples that were analyzed for DSAs was performed. According to their test results, the recipients were divided into a DSA-positive group and a DSA-negative group. Postoperative liver transplantation biopsies were performed in patients with abnormal liver function. The liver condition and prognosis of the recipients were recorded, and their association was analyzed. A total of 48 recipients were followed up for $2.7 \pm 0.8$ years. DSA positivity was detected in 10 cases $(20.8 \%)$. One case was positive for HLA class I and HLA class II antibodies, whereas 9 cases were positive for HLA class II antibodies, and the gene loci were HLA-DR and/or DQ. Antibody-mediated rejection (AMR) occurred in four of 10 patients in the DSA-positive group. Liver function was abnormal in 3 of 38 cases in the DSA-negative group. Multivariate analysis revealed that DSA positivity was an independent risk factor for liver insufficiency and long-term survival of recipients. In addition, Kaplan-Meier survival analysis demonstrated that there were significant differences in the survival of graft recipients between the DSA-positive group and the DSA-negative group $(\mathrm{P}<0.05)$. The positivity of DSAs after pediatric liver transplantation was closely related to the occurrence of AMR. These results suggested that DSAs should be routinely monitored post-operatively, and that DSA-positive recipients should be screened as soon as possible and given appropriate treatment.
\end{abstract}

Correspondence to: Professor Dai-Hong Li, Department of Blood Transfusion, Tianjin First Central Hospital, 24 Fukang Road, Tianjin 300192, P.R. China

E-mail: 1dh_hla@163.com

Key words: pediatric liver transplantation, donor-specific human leukocyte antigen antibodies, incidence of liver events, antibody-mediated rejection, long-term survival

\section{Introduction}

Increasing evidence has indicated that the existence of donor-specific human leukocyte antigen (HLA) antibodies (DSAs) may adversely affect the long-term survival of grafts (1). DSAs in kidney and heart transplant recipients have been associated with acute T-cell-mediated rejection, antibody-mediated rejection (AMR), progression to chronic rejection, late graft dysfunction, vasculopathy and allograft loss (2-6).

In adult liver transplantation, the effect of DSAs on long-term survival is controversial, but DSAs may be a risk factor for poor survival (7-9). Patients undergoing liver transplantation with preformed DSAs have been indicated to be at increased risk of hyperacute rejection (10) and AMR within the first weeks after transplantation (11-13). In addition, DSAs have been associated with chronic rejection $(14,15)$, accelerated fibrosis $(16,17)$ and anastomotic biliary strictures (18). Compared with adult recipients, pediatric liver transplant recipients exhibit a higher incidence of DSAs after liver transplantation. It has been reported that the positive rate of DSAs in pediatric liver transplant recipients can be as high as 54\% (19). However, the relationship between the presence of DSAs and AMR after pediatric liver transplantation and how it affects the survival of allogeneic liver transplant recipients is not clear.

The purpose of the present study was to analyze the effect of DSAs on the liver function and survival of 48 pediatric patients undergoing liver transplantation at the Tianjin First Central Hospital (Tianjin, China).

\section{Materials and methods}

Patients and samples. A retrospective analysis of 48 pediatric patients undergoing liver transplantation (age, 0-11 years) at the Tianjin First Central Hospital, enrolled between January 2015 and December 2018, was conducted. The following criteria were used to select patients for the present study: i) All children with complete follow-up data after liver transplantation; and ii) all pediatric liver transplant recipients who received immunosuppressive therapy consisting of tacrolimus combined with corticosteroids.

Immunosuppression. All recipients were treated with tacrolimus and corticosteroids. Methylprednisolone and 
basiliximab were also used to treat patients following pediatric liver transplantations; basiliximab was given on the fourth day post-operatively. Sequential treatment with methylprednisolone was administered post-operatively and stopped at 6 months. Tacrolimus was administered on the second day after liver transplantation, and the trough concentration $(7-10 \mathrm{ng} / \mathrm{ml})$ was maintained up to 3 months after pediatric liver transplantation. Following detection of DSAs, the recipients were treated with mycophenolate mofetil (MMF; $600 \mathrm{mg} / \mathrm{m}^{2}$ per dose twice daily).

Diagnostic criteria for AMR following pediatric liver transplantation. The diagnostic criteria for AMR after pediatric liver transplantation included the following: i) early liver transplantation insufficiency; ii) diffuse vascular endothelial injury and small perivascular inflammation; iii) high DSA positivity; iv) strong diffuse C4d linear staining of liver tissue; and v) improvement in liver function (measured using standard biochemical tests), decreased DSA level, improvement in liver histology (such as fibrosis and inflammation) and disappearance of C4d deposition after anti-AMR treatment.

HLA typing and HLA antibody determination. All patients and donors were typed for HLA-A, -B, -DRB1 and -DQB1. HLA class I and II typing was performed by molecular methods (PCR-sequence-specific oligonucleotide techniques; One Lambda Inc.) (20). The detection of HLA antibodies was performed using Lifecodes single-antigen beads class I and II (Immucor Inc.), according to the manufacturer's protocol (21). Antibody results of liver transplantation recipients were compared with the HLA of the corresponding donor to determine whether they were donor-specific. The interpretation criteria for positive samples were as follows: Mean fluorescence intensity (MFI) $>10,000$ was strongly positive, 4,000< MFI $<10,000$ was moderately positive, $750<\mathrm{MFI}<4,000$ was weakly positive and $<750$ was negative.

Liver histology. Liver tissue specimens obtained by ultrasound-guided biopsy were fixed for $12 \mathrm{~h}$ in $4 \%$ formaldehyde solution at room temperature, and $3-\mu \mathrm{m}$ paraffin-embedded sections were cut according to the conventional procedure. For H\&E staining, hematoxylin staining was performed for $5 \mathrm{~min}$, followed by immersion in $1 \%$ hydrochloric acid alcohol for $30 \mathrm{sec}$, light ammonia water for $30 \mathrm{sec}$, eosin staining for $1 \mathrm{~min}$ and gradient alcohol dehydration at room temperature (all from Wexis Group Limited). For Masson's trichrome, the slides were stained with hematoxylin for 3-5 min, followed by Ponceau acid red for 5-8 min at room temperature. After washing with water, the slides were sequentially immersed in phosphomolybdic acid for $3 \mathrm{~min}$, acetic acid for $20 \mathrm{sec}$, water-soluble aniline blue for $30 \mathrm{sec}, 95 \%$ ethanol and xylene for dehydration at room temperature (all from Beijing Yili Fine Chemicals co., Ltd.). For C4d staining, after antigen retrieval (high pressure for $3 \mathrm{~min}$ at $120^{\circ} \mathrm{C}$ ), the anti-C4d antibody (cat no. ab187931; Abcam) was incubated at $4^{\circ} \mathrm{C}$ overnight, followed by HRP-labeled anti-mouse $\operatorname{IgG}$ antibody (provided in the ultraView Universal DAB Detection Kit; cat. no. 760-500;
Table I. Characteristics of pediatric liver transplant recipients $(n=48)$.

\begin{tabular}{lc} 
Characteristics & Data at transplantation \\
\hline Age, mean \pm SD (range) & $3.7 \pm 2.6(1-11)$ \\
Sex (male/female) & $27 / 21$ \\
Clinical diagnosis (n) & 38 \\
Biliary atresia & 1 \\
Autoimmune liver cirrhosis & 1 \\
Congenital bile duct dilatation & 1 \\
Bile cirrhosis & 1 \\
Alagille syndrome & 6 \\
Cholestasis & \\
Liver transplant type (n) & 35 \\
Parental transplantation & 13 \\
Liver transplantation after donor death & \\
Blood type combination (n) & 31 \\
Identical & 17 \\
Compatible &
\end{tabular}

Roche Diagnostics) at $37^{\circ} \mathrm{C}$ for $30 \mathrm{~min}$, incubation with 3,3-diaminobenzidine at room temperature for $5 \mathrm{~min}$ for color development and hematoxylin counterstain for $30 \mathrm{sec}$ (both from Roche Applied Science).

Statistical analysis. Statistical analysis was performed using SPSS (version 20.0; IBM Corp.) and GraphPad Prism (version 5.0; GraphPad Software, Inc.) software. Continuous variables are presented as the mean \pm standard deviation for normally distributed data and as median (range) when the values were not normally distributed. The differences between the groups were tested by independent samples t-test or $\chi^{2}$ test, as appropriate. The Mann-Whitney $U$ test was used when parameters exhibited a non-normal distribution. Kaplan-Meier survival analysis was performed to analyze clinical events following liver transplantation, and statistical significance was determined by log rank testing. Multivariate analyses were performed using the Cox proportional hazards regression model. $\mathrm{P}<0.05$ was considered to indicate a statistically significant difference.

\section{Results}

Baseline characteristics. All patients were children who underwent a primary liver transplant. Patient characteristics are outlined in Table I. The mean recipient age was $3.7 \pm 2.6$ years. The primary disease of $38(79.2 \%)$ patients was biliary atresia. A total of 35 livers were from parental donors and 13 livers were from deceased organ donors.

Prevalence of DSAs in pediatric liver transplantation. It was observed that 10 of $48(20.8 \%)$ pediatric patients developed DSAs post-liver transplantation (Table II). One of the 10 patients $(10 \%)$ developed DSAs against HLA class I and II antigens, and nine (90\%) developed DSAs against HLA class II antigens. Six of the 10 patients $(60 \%)$ developed one DSA, 


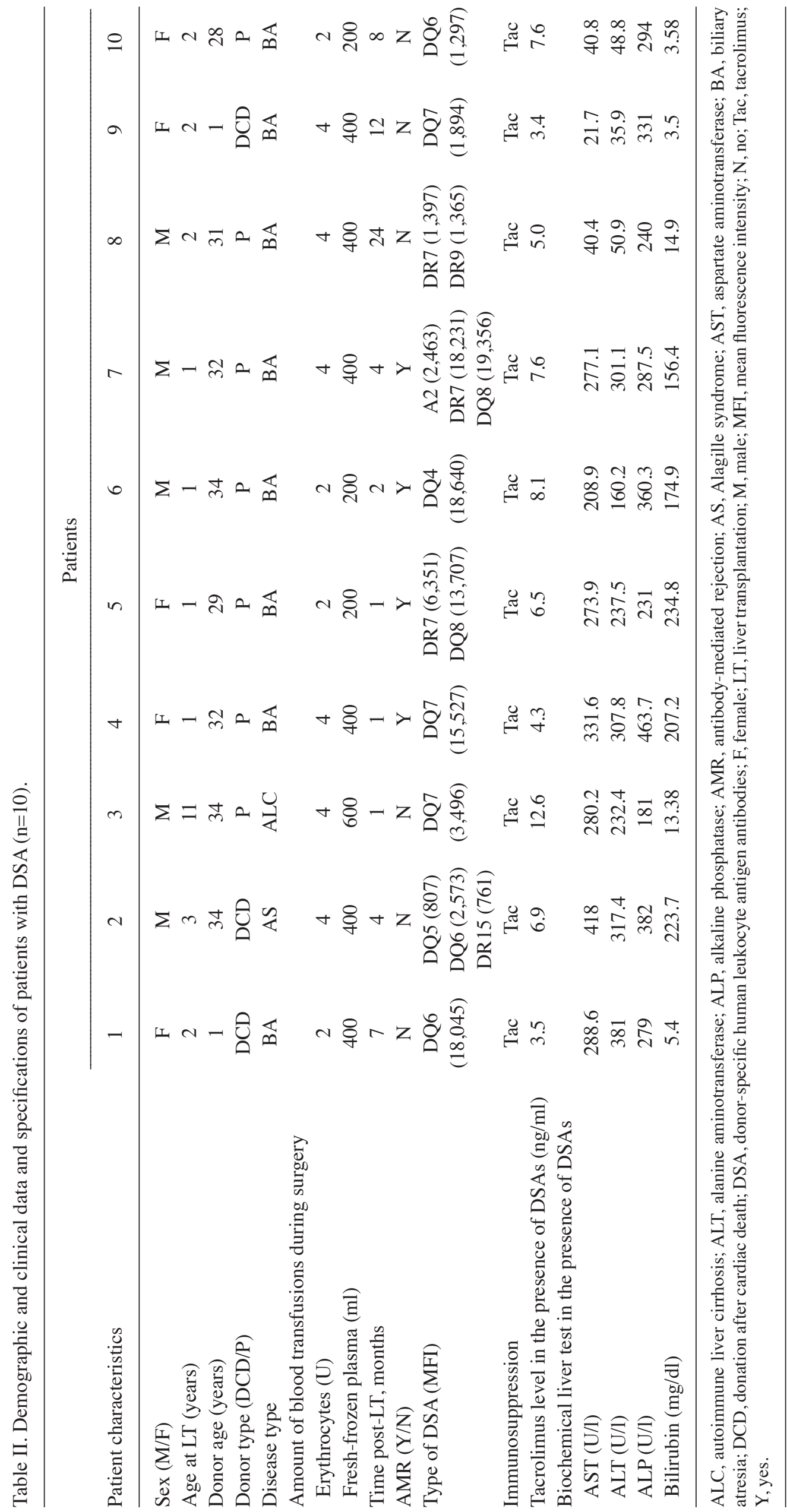


Table III. Comparison of demographic and clinical parameters between pediatric transplant patient groups.

\begin{tabular}{lccr}
\hline Characteristics & DSA group & Non-DSA group & P-value \\
\hline Number of patients & 10 & 38 & \\
Sex (male/female) & $5 / 5$ & $22 / 16$ & 0.6543 \\
Age at LT, mean \pm SD (years) & $2.6 \pm 0.9$ & $2.6 \pm 0.4$ & 0.9961 \\
Donor age, mean \pm SD (years) & $25 \pm 4.2$ & $26 \pm 1.9$ & 0.9321 \\
Donor type (DCD/Parental) & $3 / 7$ & $10 / 28$ & 0.8156 \\
Amount of blood transfusions during surgery & & & \\
Erythrocytes (U) & $3.2(2-4)$ & $2.9(2-4)$ & 0.4745 \\
Fresh-frozen plasma (ml) & $360(200-400)$ & $340(200-600)$ & 0.8329 \\
Number of transfusions, mean \pm SD (n) & $0.9 \pm 0.32$ & $0.74 \pm 0.45$ & 0.0110 \\
Time post-LT, mean \pm SD (months) & $7.4 \pm 4.5$ & $17.5 \pm 7.8$ & 0.0091 \\
Acute rejection (Y/N) & $6 / 4$ & $3 / 35$ & 0.0010 \\
Antibody-mediated rejection (Y/N) & $4 / 6$ & $0 / 38$ & 0.0010 \\
Tacrolimus level in the presence of DSA (ng/ml) & $6.6 \pm 0.9$ & $3.9 \pm 0.3$ & 0.0005 \\
Biochemical liver test at biopsy & & & $<0.0001$ \\
ALT (U/l) & $227.4 \pm 46.0$ & $43.0 \pm 7.5$ & $<0.0001$ \\
AST (U/l) & $198.1 \pm 36.4$ & $43.6 \pm 3.8$ & $<.2684$ \\
ALP (U/l) & $305.0 \pm 26.0$ & $261.8 \pm 17.9$ & 00001 \\
Bilirubin (mg/dl) & $103.8 \pm 32.7$ & $7.6 \pm 1.0$ & \\
\hline
\end{tabular}

ALC, autoimmune liver cirrhosis; AS, Alagille syndrome; ALP, alkaline phosphatase; ALT, alanine aminotransferase; AST, aspartate aminotransferase; BA, biliary atresia; DCD, donation after cardiac death; DSA, donor-specific human leukocyte antigen antibodies; LT, liver transplantation; MFI, mean fluorescence intensity; N, no; Y, yes.

Table IV. Cox regression analysis of patient survival predictors.

\begin{tabular}{lcc}
\hline & \multicolumn{2}{c}{ Multivariate analysis } \\
\cline { 2 - 3 } Variables & $95 \% \mathrm{CI}$ & P-value \\
\hline DSAs & $0.182-0.952$ & 0.038 \\
Patient age <2-years-old & $0.678-0.996$ & 0.045 \\
Donor age $<2$-years-old & $0.967-1.042$ & 0.837 \\
Donor type & $0.124-1.071$ & 0.066 \\
\hline
\end{tabular}

CI, confidence interval.

2 patients (20\%) developed two DSAs and 2 patients $(20 \%)$ developed three DSAs. The locus-specificity of DSAs was as follows: One (10\%) against the A locus, 4 (40\%) against the DR locus and 9 (90\%) against the DQ locus. AMR occurred after pediatric liver transplant in in 4 of the 10 patients $(40 \%)$. In patients with AMR, the mean MFI of HLA-DQ was 16,807 (range, 13,707-19,356) and the mean MFI of HLA-DR was 12,291 (range, 6,351-18,231). In patients with no AMR, the mean MFI of HLA-DQ was 5,461 (range, 1,297-18,045) and the mean MFI of HLA-DR was 1,079 (range, 761-1,397).

Differences in various indexes in different pediatric liver transplantation groups. According to the HLA classification of donors and recipients, and the DSA detection results, the recipients were divided into two groups: A DSA-positive group and a DSA-negative group. There was no significant difference in age, sex, donor age, donor type and intraoperative blood transfusion between the two groups $(\mathrm{P}>0.05)$. There were significant differences in the tacrolimus level in the presence of DSA, postoperative alanine aminotransferase (ALT), aspartate aminotransferase (AST), total bilirubin and follow-up time (time post-LT) between the two groups $(\mathrm{P}<0.05$; Table III).

Impact of DSAs on patient and allograft survival. The role of DSAs in predicting patient survival was then analyzed using Cox proportional hazard analysis (Table IV). The multivariate model identified DSAs and recipient age $<2$-years-old as independent predictors of patient death $(\mathrm{P}<0.05)$.

Liver biopsies were performed in 10 patients with abnormal liver function in the DSA-positive group (7 cases) and DSA-negative group ( 3 cases). Among 7 cases in the DSA-positive group, the pathological results of 4 cases indicated an antibody-mediated rejection, and 3 of the 4 cases were positive for $\mathrm{C} 4 \mathrm{~d}$ (Fig. 1). Two cases demonstrated T-cell-mediated rejection. The 3 cases in the DSA-negative group indicated a T-cell-mediated rejection. Kaplan-Meier survival analysis revealed that there was a significant difference in the survival of graft recipients between the DSA-positive and the DSA-negative group (Fig. 2; $\mathrm{P}<0.05$ ).

Treatment and outcome of AMR in DSA-positive recipients. Of the 10 DSA-positive recipients, four had AMR. Liver function returned to normal after hormone therapy. All four patients with AMR were treated with MMF and 3 of the patients were treated with plasma exchange 1-3 times. During 
A

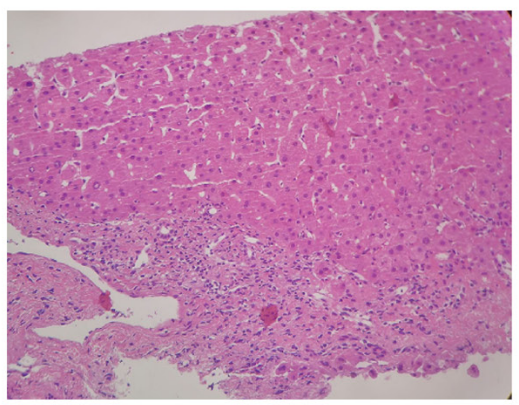

B

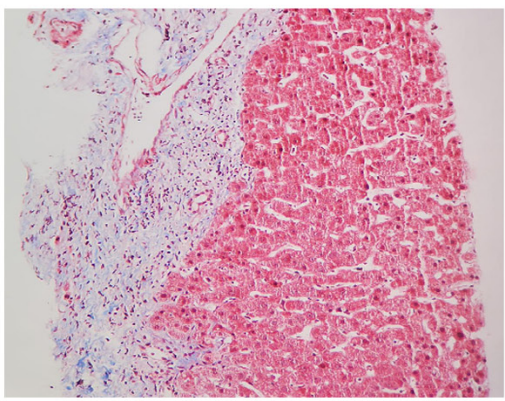

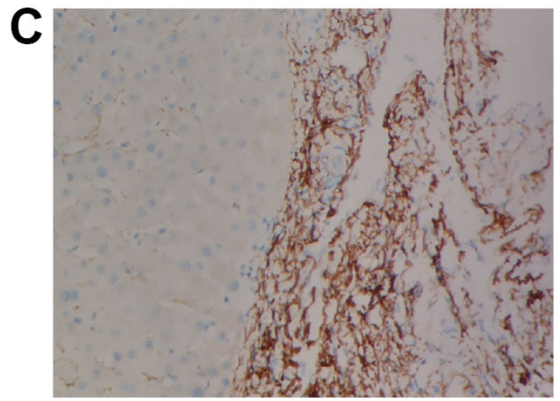

Figure 1. Pathological manifestations of antibody-mediated rejection in liver allografts. (A) Hematoxylin and eosin staining. Proliferation and expansion of small veins in the portal area, and lymphocyte and neutrophil infiltration were detected. Lymphocyte and neutrophil infiltration were also seen in the liver sinusoid. (B) Masson staining. Fibrous tissue was observed. (C) C4d staining. C4d positive expression was detected in the venule and hepatic sinusoid in the portal area.

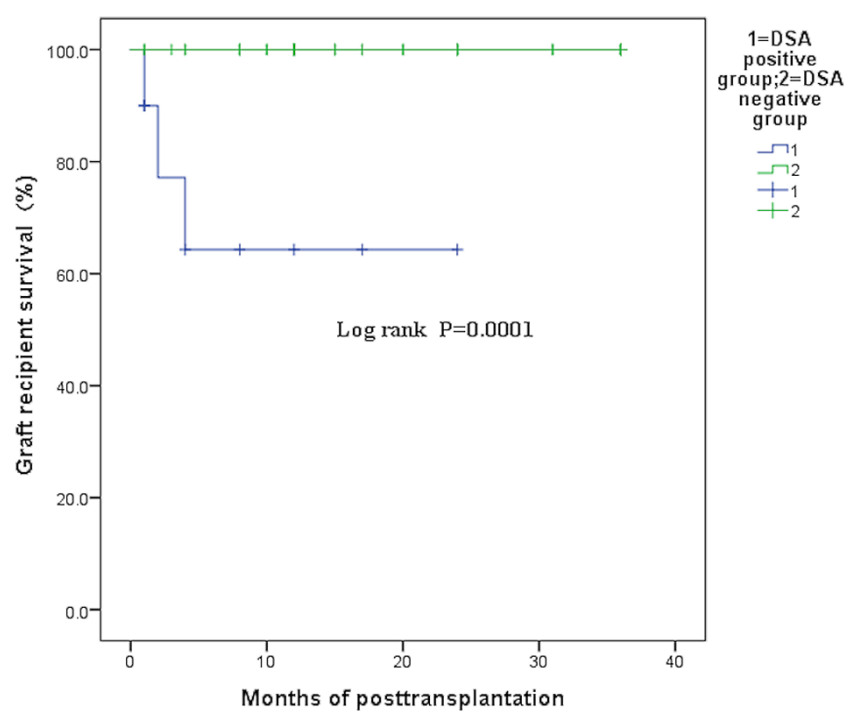

Figure 2. Graft recipient survival of the DSA-positive and the DSA-negative group. DSA, donor-specific human leukocyte antigen antibodies.

and after plasma exchange therapy, human immunoglobulin (intravenous immunoglobulin, $2.5 \mathrm{~g} / \mathrm{day}$ ) was administered intravenously. One patient was treated with bortezomib five times, and the other three patients were treated with rituximab once each. During treatment, except for the routine daily use of MMF, other treatment methods were carried out alternately. Among the patients with AMR, only one case was cured after treatment, and the other three cases finally underwent re-transplantation.

\section{Discussion}

The liver is recognized as an immune-privileged organ (22); therefore, AMR is less common after liver transplantation (23). However, the humoral immunological mechanism of acute rejection after liver transplantation is consistent with that of other organ transplantations (24). A re-evaluation of the importance of DSAs in liver transplants was required, and the present study demonstrated a higher risk of rejection and decreased allograft survival in DSA-positive patients.

In the present study, it was observed that DSAs against HLA class II antigens were more common than those against class I antigens and represented $90 \%$ of all DSAs. The HLA-II antigen is dominated by the HLA-DQ site. It was observed that in patients with AMR, the mean value of HLA-DQ MFI was $>15,000$ and the mean value of HLA-DR MFI was $>10,000$. Therefore, a high MFI value was closely related to the occurrence of AMR. Previous research has demonstrated that the occurrence of AMR, bile duct complications and hepatic fibrosis in DSA-positive liver transplantation recipients is closely related to the characteristics, intensity and IgG classification of antibodies (25). In a retrospective cohort study, such as that by Kaneku et al (26), DSA analysis of serum samples before and after transplantation was performed in 749 adult liver transplant recipients. It was found that $8.1 \%$ of patients developed DSAs 1 year after transplant. Almost all DSAs were targeted at HLA II antigens, most of which were targeted at HLA-DQ antigens. O'Leary and Klintmalm (27) retrospectively analyzed 79 children with good graft function $>5$ years after transplantation. The donor specificity of antibodies was identified in 67 patients; specifically, DSAs were detected in 32 cases (48\%). The DSAs were usually targeted at HLA class II (30 cases) and rarely against class I ( 2 cases). Although the liver has the ability to absorb pre-stored HLA class I antibodies, the persistence of HLA class II antibodies increases the incidence of acute and chronic rejection (27).

Another finding of the present study was that DSA-positive recipients exhibited abnormal liver function before AMR and exhibited abnormal elevation of serum transaminase, followed by hypercholanemia. O'Leary et al (28) retrospectively evaluated 1,270 cases of liver transplantation and demonstrated that immunosuppressant concentration and hormone dosage were closely related to rejection. Another study reported that the detection rate of DSAs in the non-tolerant group was $54 \%$, mainly targeting HLA class II antigens (DR, 41\%; DQ, 53\%). The average levels of AST, ALT, total bilirubin and $\gamma$-glutamyltransferase were also higher in DSA-positive patients (19).

The formation of DSAs in the early stages after organ transplantation suggests a poor prognosis, but the pathogenesis between DSAs and rejection has not been determined. In other organ transplants, such as renal, complement $\mathrm{C} 4 \mathrm{~d}$ has been recognized as a sensitive index to predict rejection; however, the role of C4d in liver transplantation has been controversial (29). 
Although it has been reported that $\mathrm{C} 4 \mathrm{~d}$ serves an important role in the prediction of rejection in DSA-positive cases, it is highly specific but not highly sensitive. Some research has shown that acute rejection after liver transplantation is closely related to the accumulation of vascular endothelial cells in the portal area. However, Ali et al (30) revealed that positive staining of $\mathrm{C} 4 \mathrm{~d}$ can be found in different liver lesions, i.e., acute cell rejection (52\%), chronic catheterization rejection $(50 \%)$, recurrent liver disease (48\%), preservation injury (18\%) and liver necrosis (54\%). Furthermore, C4d positivity was rarely found in $\mathrm{ABO}$ blood group-compatible liver transplantation, but it was closely related to liver fibrosis after transplant. Musat et al (15) performed liver biopsies in 43 patients with acute or chronic rejection after liver transplantation. There was a significant positive association between $\mathrm{C} 4 \mathrm{~d}$ deposition and DSA intensity (MFI). The incidence of chronic rejection among DQ-DSA-positive patients was higher than that among DQ-DSA-negative patients. The higher the MFI value of DSAs, the higher the risk of chronic rejection. Del Bello et al (31) performed a retrospective analysis of 152 patients with liver transplantation and demonstrated that 21 patients $(14 \%)$ developed DSAs, including 5 patients with C1q-DSA (24\%) and 9 patients (43\%) with AMR. The positive rate of $\mathrm{C} 4 \mathrm{~d}$ staining was higher in liver biopsies from patients with AMR $(\mathrm{P}<0.0001)$. In the present study, liver biopsies were performed in 10 patients with abnormal liver function in the DSA-positive group. The pathological results of four cases revealed that the cellular rejection was grade 0 , and three cases were positive for $\mathrm{C} 4 \mathrm{~d}$, suggesting that systemic fluid rejection should be further assessed. C1q-DSA should also be further assessed. In recent years, additional knowledge on complement C1q has been obtained (32). It has been revealed that the damage caused by DSA was related to its own ability to bind C1q. C1q-DSA is considered to exhibit potential cytotoxicity and has been associated with acute rejection and graft loss (33).

In the present study, all the patients with AMR were treated with MMF, and 3 of them were treated with plasma exchange. During and after plasma exchange therapy, human immunoglobulin was administered intravenously. One patient was treated with bortezomib, and the other 3 patients were treated with rituximab. Among the patients with AMR, only one case was cured after treatment, and the other three cases finally underwent re-transplantation. DSAs are closely related to rejection after liver transplantation. Common treatments for abnormal liver function caused by DSAs include plasma exchange, immunoglobulin, rituximab and bortezomib. Bortezomib is used to treat AMR; however, considering the increased risk of viral hepatitis and other infections, the pros and cons should be assessed prior to treatment (34-36). In a study by Paterno et al (13), bortezomib was used to treat three ABO-compatible liver transplant recipients with AMR. These patients developed a severe, acute rejection of steroids and antithymocyte globulin resistance; they also had histological evidence of plasma cell infiltration. After treatment with bortezomib, the liver function of all patients with $\mathrm{C} 4 \mathrm{~d}$ positivity and high DSA levels improved or was normal, the deposition of C4d disappeared and the level of DSAs decreased significantly.

The present study had some limitations. Firstly, HLA antibody analysis in pediatric liver transplants is not a routine test for all patients before transplant. Thus, the authors were unable to determine whether the detected antibodies in patients were preformed or de novo. Secondly, the sample size in the present study was small; more samples need to be collected to further analyze the relationship between DSAs and graft loss in patients. Thirdly, the follow-up time of pediatric liver transplants needs to be extended to study the 5 -year graft survival rate of children. Finally, more clinical data and practical experience should be accumulated in the diagnosis and treatment of AMR after liver transplantation in children. When the diagnosis of AMR is unknown or highly suspected, liver biopsies and DSA tests should be performed in a timely manner, and $\mathrm{C} 4 \mathrm{~d}, \mathrm{IgG}$ subclass, $\mathrm{Clq}$ and $\mathrm{C} 3 \mathrm{~d}$ should be assessed at the same time (37). In conclusion, regular monitoring of DSA levels may have an important role in predicting graft survival and DSA treatment choice.

\section{Acknowledgements}

Not applicable.

\section{Funding}

The present study was supported by the Tianjin Natural Science Foundation (grant no. 17JCYBJC27500) and the China Organ Transplant Development Foundation 'Elite Project' (grant no. 2019JYJH03).

\section{Availability of data and materials}

The datasets used and/or analyzed during the current study are available from the corresponding author on reasonable request.

\section{Authors' contributions}

DHL conceived the study. WL performed the research, analyzed the data and wrote the first draft of the manuscript. KW collected the clinical data and revised the draft. YLX and CL performed the measurement of DSA and HLA typing. WG screened the clinical data. All authors read and approved the final manuscript.

\section{Ethics approval and consent to participate}

Written informed consent was obtained from the patients' parents/guardians. The present study was approved by the Medical Ethics Committee of Tianjin First Central Hospital (approval no. 2015017S).

\section{Patient consent for publication}

Not applicable.

\section{Competing interests}

The authors declare that they have no competing interests.

\section{References}

1. Vionnet J, Sempoux C, Pascual M, Sánchez-Fueyo A and Colmenero J: Donor-specific antibodies in liver transplantation. Gastroenterol Hepatol 43: 34-45, 2020 (In English, Spanish). 
2. Kannabhiran D, Lee J, Schwartz JE, Friedlander R, Aull M, Muthukumar T, Campbell S, Epstein D, Seshan SV, Kapur S, et al: Characteristics of circulating donor human leukocyte antigen-specific immunoglobulin $\mathrm{G}$ antibodies predictive of acute antibody-mediated rejection and kidney allograft failure. Transplantation 99: 1156-1164, 2015.

3. Mohan S, Palanisamy A, Tsapepas D, Tanriover B, Crew RJ, Dube G, Ratner LE, Cohen DJ and Radhakrishnan J: Donor-specific antibodies adversely affect kidney allograft outcomes. J Am Soc Nephrol 23: 2061-2071, 2012.

4. Einecke G, Sis B, Reeve J, Mengel M, Campbell PM, Hidalgo LG, Kaplan B and Halloran PF: Antibody-mediated microcirculation injury is the major cause of late kidney transplant failure. Am J Transplant 9: 2520-2531, 2009.

5. Venick RS, Farmer DG, McDiarmid SV, Duffy JP, Gordon SA Yersiz H, Hong JC, Vargas JH, Amment ME and Busuttil RW: Predictors of survival following liver transplantation in infants: A single-center analysis of more than 200 cases. Transplantation 89: 600-605, 2010.

6. Bishara A, Brautbar C, Eid A, Scherman L, Ilan Y and Safadi R: Is presensitization relevant to liver transplantation outcome? Hum Immunol 63: 742-750, 2002.

7. Muro M, López-Álvarez MR, Campillo JA, Marin L, Moya-Quiles MR, Bolarin JM, Botella C, Salgado G, Martinez P, Sánchez-Bueno F, et al: Influence of human leukocyte antigen mismatching on rejection development and allograft survival in liver transplantation: Is the relevance of HLA-A locus matching being underestimated? Transpl Immunol 26: 88-93, 2012.

8. Kaczmarek I, Deutsch MA, Kauke T, Beiras-Fernandez A, Schmoeckel M, Vicol C, Sodian R, Reichart B, Spannagl M and Ueberfuhr P: Donor-specific HLA alloantibodies: Long-term impact on cardiac allograft vasculopathy and mortality after heart transplant. Exp Clin Transplant 63: 229-235, 2008.

9. Smith JD, Banner NR, Hamour IM, Ozawa M, Goh A, Robinson D, Terasaki PI and Rose ML: De novo donor HLA-specific antibodies after heart transplantation are an independent predictor of poor patient survival. Am J Transplant 11: 312-319, 2011.

10. Taner T, Gandhi MJ, Sanderson SO, Poterucha CR, De Goey SR, Stegall MD and Heimbach JK: Prevalence, course and impact of HLA donor-specific antibodies in liver transplantation in the first year. Am J Transplant 12: 1504-1510, 2012.

11. Starzl TE, Demetris AJ, Todo S, Kang Y, Tzakis A, Duquesnoy R, Makowka L, Banner B, Concepcion W and Kendrick A: Evidence for hyperacute rejection of human liver grafts: The case of the canary kidneys. Clin Transplant 3: 37-45, 1989.

12. Kozlowski T, Rubinas T, Nickeleit V, Woosley J, Schmitz J, Collins D, Hayashi P, Passannante A and Andreoni K: Liver allograft antibody-mediated rejection with demonstration of sinusoidal $\mathrm{C} 4 \mathrm{~d}$ staining and circulating donor-specific antibodies. Liver Transpl 17: 357-368, 2011

13. Paterno F, Shiller M, Tillery G, O'Leary JG, Susskind B, Trotter J and Klintmalm GB: Bortezomib for acute antibody-mediated rejection in liver transplantation. Am J Transplant 12: 2526-2531, 2012.

14. Musat AI, Pigott CM, Ellis TM, Agni RM, Leverson GE, Powell AJ, Richards KR, D'Alessandro AM and Lucey MR: Pretransplant donor-specific anti-HLA antibodies as predictors of early allograft rejection in ABO-compatible liver transplantation. Liver Transpl 19: 1132-1141, 2013.

15. Musat AI, Agni RM, Wai PY, Pirsch JD, Lorentzen DF, Powell A, Leverson GE, Bellingham JM, Fernandez LA, Foley DP, et al: The significance of donor-specific HLA antibodies in rejection and ductopenia development in ABO compatible liver transplantation. Am J Transplant 11: 500-510, 2011.

16. Demetris AJ, Markus BH, Burnham J, Nalesnik M, Gordon RD, Makowka L and Starzl TE: Antibody deposition in liver allografts with chronic rejection. Transplant Proc 19 (4 Suppl 5): S121-S125, 1987.

17. Del Bello A, Congy-Jolivet N, Muscari F, Lavayssière L, Esposito L, Cardeau-Desangles I, Guitard J, Dörr G, Suc B, Duffas JP, et al: Prevalence, incidence and risk factors for donor-specific anti-HLA antibodies in maintenance liver transplant patients. Am J Transplant 14: 867-875, 2014.

18. Miyagawa-Hayashino A, Yoshizawa A, Uchida Y, Egawa H, Yurugi K, Masuda S, Minamiguchi S, Maekawa T, Uemoto S and Haga H: Progressive graft fibrosis and donor-specific human leukocyte antigen antibodies in pediatric late liver allografts Liver Transpl 18: 1333-3342, 2012.
19. Wozniak LJ, Hickey MJ, Venick RS, Vargas JH, Farmer DG, Busuttil RW, McDiarmid SV and Reed EF: Donor-specific HLA antibodies are associated with late allograft dysfunction after pediatric liver transplantation. Transplantation 99: 1416-1422, 2015.

20. Dalva K and Beksac M: HLA typing with sequence-specific oligonucleotide primed PCR (PCR-SSO) and use of the Luminex technology. Methods Mol Med 134: 61-69, 2007.

21. Yoshizawa A, Egawa H, Yurugi K, Hishida R, Tsuji H, Ashihara E, Miyagawa-Hayashino A, Teramukai S, Maekawa T, Haga $\mathrm{H}$ and Uemoto S: Significance of semiquantitative assessment of preformed donor-specific antibody using luminex single bead assay in living related liver transplantation. Clin Dev Immunol 2013: 972705, 2013.

22. Chen ZH: Problems and significance of liver allograft as an immunologically privileged organ. Zhonghua Gan Zang Bing Za Zhi 13: 221, 2005 (In Chinese)

23. Guo H: Brief summary of recent findings on pathology of antibody-mediated rejection in organ transplantation. Chin J Transplant (Electronic Edition) 6: 138-143, 2012.

24. Zhou J and Shao CK: Advances of cellular and molecular immunology of acute rejection in liver transplantation. Chin J Organ Transplant 6: 381-383, 2007.

25. Valcnzucla NM, Hickey MJ and Reed EF: Antibody subclass repertoire and graft outcome following solid organ transplantation. Front Immunol 7: 433, 2016.

26. Kaneku H, O'Leary JG, Bannuelos N, Jenning LW, Susskind BM, Klintmalm GB and Terasaki PI: De novo donor-specific HLA antibodies decrease patient and graft survival in liver transplant recipients. Am J Transplant 13: 1541-1548, 2013.

27. O'Leary JG and Klintmalm GB: Impact of donor-specific antibodies on results of liver transplantation. Curr Opin Organ Transplant 18: 279-284, 2013

28. O'Leary JG, Kaneku H, Jennings LW, Banuelos N, Susskind BM, Terasaki PI and Klintmalm GB: Preformed class II donor-specific antibodies are associated with an increased risk of early rejection after liver transplantation. Liver Transpl 19: 973-980, 2013.

29. Böhming GA, Exner M, Habicht A, Schillinger M, Lang U, Kletzmayr J, Säemann MD, Hörl WH, Watschinger B and Regele H: Capillary C4d deposition in kidney allografts: A specific marker of alloantibody-dependent graft injury. J Am Soc Nephrol 13: 1091-1099, 2002

30. Ali S, Ormsby A, Shah V, Segovia MC, Kantz KL, Skorupski S, Eisenbrey AB, Mahan M and Huang MA: Significance of complement split product $\mathrm{C} 4 \mathrm{~d}$ in $\mathrm{ABO}$-compatible liver allograft: Diagnosing utility in acute antibody mediated rejection. Transpl Immunol 26: 62-69, 2012

31. Del Bello A, Congy-Jolivet N, Danjoux M, Muscari F, Lavayssière L, Esposito L, Cardeau-Desangles I, Guitard J, Dörr G, Milongo D, et al: De novo donor-specific anti-HLA antibodies mediated rejection in liver-transplant patients. Transpl Int 28: 1371-1382, 2015.

32. Kovandova B, Slavcev A, Sekerkova Z, Honsova E and Trunecka P: Antibody-mediated rejection after liver transplantation-relevance of C1q and C3d-binding antibodies. HLA 92 (Suppl 2): S34-S37, 2018.

33. Sutherland SM, Chen G, Sequeira FA, Lou CD, Alexander SR and Tyan DB: Complement-fixing donor-specific antibodies identified by a novel Clq assay are associated with allograft loss. Pediatr Transplant 16: 12-17,2012.

34. Wilson CH, Agarwal K, Carter V, Burt AD, Hübscher S, Talbot D, Jaques BC and Manas DM: Late humoral rejection in a compliant ABO-compatible liver transplant recipient. Transplantation 82: 988-989, 2006

35. Watson R, Kozlowski T, Nickeleit V, Woosley JT, Schmitz JL, Zacks SL, Fair JH, Gerber DA and Andreoni KA: Isolated donor specific alloantibody-mediated rejection after $\mathrm{ABO}$ compatible liver transplantation. Am J Transplant 6: 3022-3029, 2006.

36. Kamar N, Lavayssière L, Muscari F, Selves J Guilbeau-Frugier C, Cardeau I, Esposito L, Cointault O, Nogier MB, Peron JM, et al: Early plasmapheresis and rituximab for acute humoral rejection after ABO-compatible liver transplantation. World J Gastroenterol 15: 3426-3430, 2009.

37. Couchonnal E, Rivet C, Ducreux S, Dumortier J, Bosch A, Boillot O, Collardeau-Frachon S, Dubois R, Hervieu V, André $\mathrm{P}$, et al: Deleterious impact of C3d-binding donor-specific anti-HLA antibodies after pediatric liver transplantation. Transpl Immunol 45: 8-14, 2017.

This work is licensed under a Creative Commons Attribution-NonCommercial-NoDerivatives 4.0 International (CC BY-NC-ND 4.0) License. 